\title{
Congenital granular cell epulis: a case report with immunohistochemistry
}

\begin{abstract}
Payman A. Rashi ${ }^{(1)}$, Jalal A. Jalal ${ }^{(1)}$, Muhammed Yakin ${ }^{(2)}$
Congenital granular cell epulis is a rare benign tumor of soft tissue in newborns. In most cases it arises from the anterior part of the maxillary alveolar ridge and is ten times more prevalent in females than males. We present a case report of a 2-month-old female infant, who presented with a mass on the gingival mucosa. The lesion was completely removed by simple excision. A final diagnosis of a congenital granular cell tumor was made by histologic and immunohistochemical examination.
\end{abstract}

\section{Key words:}

Congenital granular cell epulis, congenital epulis, histopathology, immunohistochemistry.

\footnotetext{
${ }^{1}$ College of Medicine, Hawler Medical University, Erbil, Iraq.

${ }^{2}$ School of Dentistry and Health Sciences, Charles Sturt University, Orange, NSW, Australia.

* Corresponding author E- mail: payman.rashid@hmu.edu.krd
}

\section{Introduction:}

Congenital granular cell epulis (CGCE) is a rare tumor of the newborn, also known as congenital epulis or Neumann's tumor; who was the first to describe it in 1871 . This tumor arises from the gingival mucosa, most commonly from the anterior part of the maxillary alveolar ridge, with a maxilla to mandible ratio of $3: 1$ and a female to male ratio of $10: 1 .^{1}$ It usually appears as a polypoid mass protruding out of the infant's mouth, which may interfere with respiration or feeding. ${ }^{2,3}$

The etiologic factors for CGCE are unknown and the histogenesis is uncertain. In the latest WHO classification, this lesion is classified under tumors of uncertain histogenesis. ${ }^{4}$ We report a case of CGCE, describing its clinical, histopathological, and immunohistochemical characteristics.

\section{Case report}

A two-month-old female infant was presented with a mass on the maxillary right gingival mucosa. The mass did not cause feeding or breathing difficulties. The lesion was excised and sent to the department of histopathology at the Maternity teaching Hospital in Erbil city, Kurdistan region of Iraq, for histopathological examination.

The specimen consisted of a wellcircumscribed gray mass measuring $10 \times 10 \times 5 \mathrm{~mm}$ with a firm consistency on sectioning. Microscopic examination showed thin, flattened stratified squamous epithelium devoid of rete ridges, overlying sheets of uniform, large, round to ovoid cells with granular eosinophilic cytoplasm and small, round, centrally located nuclei. The granular cells were supported by a fibrous connective tissue stroma with prominent capillary proliferation forming staghorn patterns (Figure 1).

Immunohistochemically, the tumor cells showed diffuse positivity for vimentin, focal positivity for calretinin, and negativity for neuron-specific enolase (NSE), CD31 and S100-protein (Figures 2-6).

A final diagnosis of CGCE was made based on histological and immunohistochemical findings. 


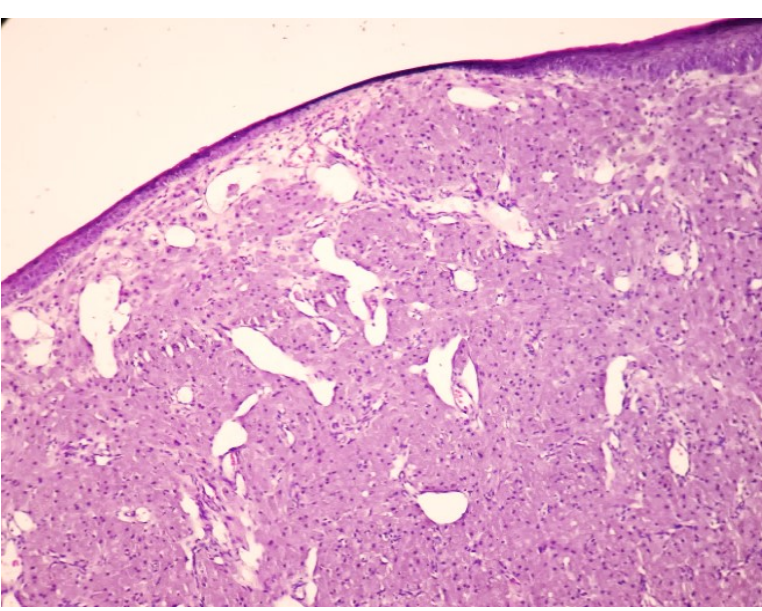

Figure 1: Photomicrograph of the lesion (H\&E 100X).

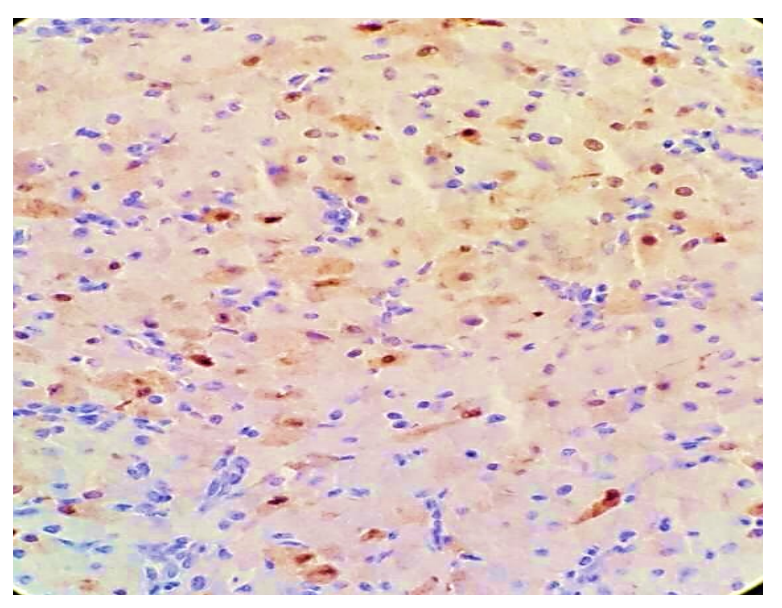

Figure (3): Focal positive staining for calretinin (IHC 100X).

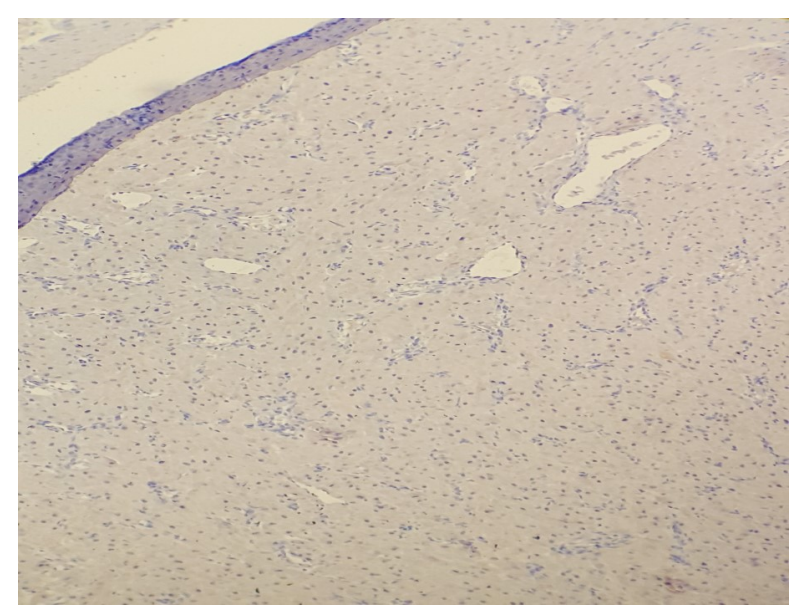

Figure (5): Negative staining for NSE (IHC 400X).

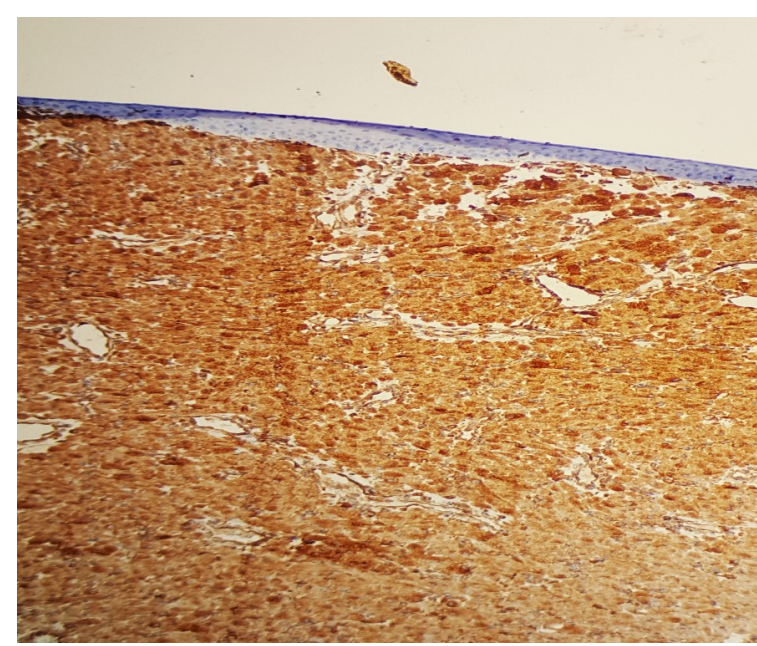

Figure (2): Diffuse and strong positivity for vimentin in the lesional cells (IHC 100X).

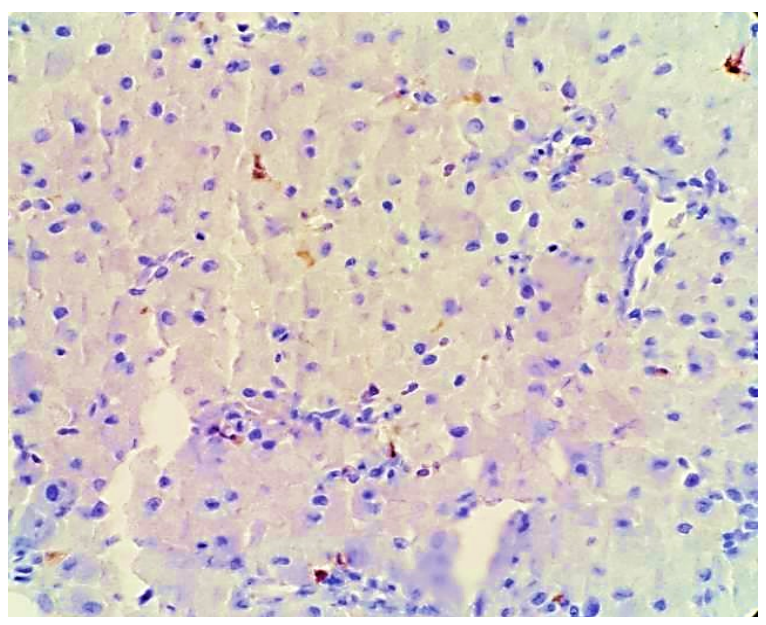

Figure (4): Negative staining of lesional cells for S100 protein. Note occasional scattered positivity in dendritic cells (IHC 100X).

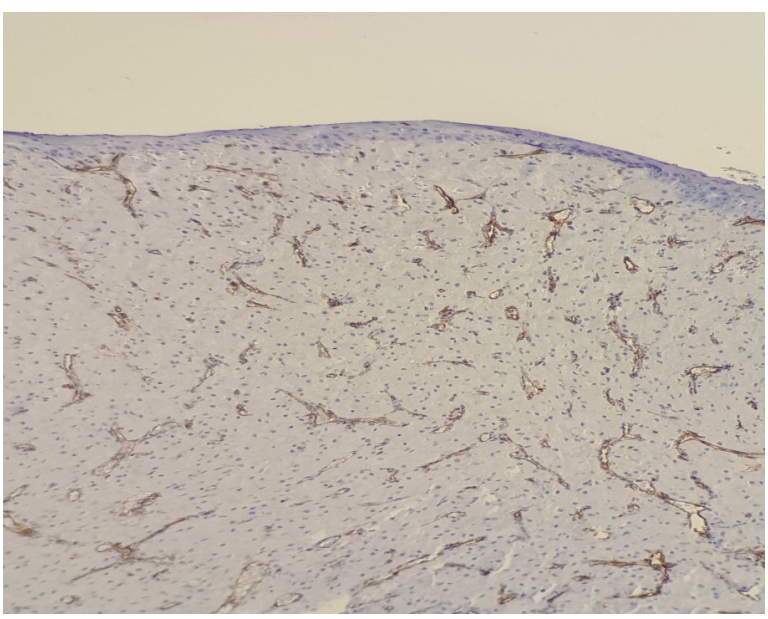

Figure (6): Negative staining for CD31. Note immunoreactivity in the capillaries (IHC 400X). 


\section{Discussion}

The first case of CGCE was published by Neumann in 1871 . It was called as congenital epulis, or Neumann's tumor. The Greek term Epulis means 'swelling on the gingiva'. The current WHO nomenclature for this lesion is congenital granular cell epulis. ${ }^{4}$ This rare benign tumor is seen only in the neonatal period and has a marked female preponderance with a female to male ratio of 10:1. It arises from the gingival mucosa, most commonly the anterior part of the maxillary alveolar ridge, although one-third of cases do arise from the mandibular gingiva and multiple lesions are seen in approximately $10 \%$ of the cases. $^{5-7}$ Reported sizes vary from several millimeters to $2 \mathrm{~cm}$, but sizes as large as 9 cm have been reported. ${ }^{7}$

This tumor is a different entity from other granular cell tumors (GCT). However, there are striking histologic similarities of the granular cells of CGCE with GCT of other sites. ${ }^{8}$ There are several distinguishing features of CGCE. Clinically, CGCE has a predilection for newborn females, anterior maxillary location, and is usually present at birth. Histologically, capillaries are arranged in a plexiform pattern and there is no pseudoepitheliornatous hyperplasia that is present in GCT. ${ }^{4,8,9}$

Different studies have suggested various origins for CGCE including fibroblastic, myoblastic, odontogenic, neurogenic, histiocytic, neuroendocrine, and endocrine. ${ }^{8}$

${ }^{-11}$ The most accepted hypothesis for the pathogenesis of CGCE is the degeneration process of undifferentiated mesenchymal cells which are capable of differentiation into multiple cell types. The immunohistochemical profile of this lesion supports the mesenchymal origin. ${ }^{8,9}$ In the present case, the immunohistochemical findings were in agreement with those supporting a mesenchymal origin. The lesional cells showed diffuse and strong positivity for vimentin and focal positivity for calretinin while the tumor cells did not react with S100-protein, CD31, or NSE, further supporting that $\mathrm{CGCE}$ and GCT are different entities.

Although the development of the tumor in the uterus and the higher incidence in females imply a hormonal mechanism, the pathogenesis probably takes place through different pathways because immunohistochemical investigations to detect estrogen and progesterone receptors in CGCE, to see whether the tumor is influenced by maternal hormones have yielded negative results. ${ }^{9,12,13}$

The main histologic differential diagnosis includes granular cell tumor (myoblastoma) because they have similar histological appearances but are S100protein positive. ${ }^{8,9}$

Because of reported cases of spontaneous regression and harmless nature of CGCL, some authors do not recommend surgical excision; they indicate excision when there is interference with breathing or feeding of the newborn. However, some other authors recommend simple surgical or laser excision with follow-up. Even with incomplete excision, the tumor has never been reported to recur. ${ }^{6}$

\section{Conclusion}

CGCE is a rare but distinct entity of uncertain histogenesis. It can easily diagnose by clinical characteristics, microscopical features and immunohistochemical patterns. Simple excision is curative.

\section{Conflicts of Interest}

The authors report no conflicts of interest.

\section{Ethical Consideration}

This study was approved by ethical committee in College of Medicine, Hawler Medical University, Erbil, Iraq.

\section{Pledge Form:}

- We certify that the manuscript does not contain any material the publication of which would violate any copyright or other personal proprietary right of any person or entity.

- We certify that the manuscript will not be submitted to other journals as long as it is in the process of evaluation and publishing in the EDJ.

- We certify that we are, responsible for all the information presented by us in the pledge form and be responsible for all the consequences. 


\section{References}

1. Conrad R, Perez MC. Congenital granular cell epulis. Archives of pathology \& laboratory medicine. 2014;138:128-31.

2. Childers EL, Fanburg-Smith JC. Congenital epulis of the newborn: 10 new cases of a rare oral tumor. Ann Diagn Pathol. 2011;15:157-61.

3. Lapid O, Shaco-Levy R, Krieger Y, Kachko L, Sagi A. Congenital epulis. Pediatrics. 2001;107:E22.

4. Allen CM, Bullerdiek J, Ro JY. Congenital granular cell epulis. In: El-Naggar AK, Chan JKC, Grandis JR, Takata T, Slootweg PJ, editors. WHO Classification of Head and Neck Tumours. 4th ed. Lyon: IARC; 2017. p. 119.

5. Eghbalian F, Monsef $A$. Congenital epulis in the newborn, review of the literature and a case report. Journal of pediatric hematology/oncology. 2009;31:198-9.

6. O'Brian FV, Pielou WD. Congenital epulis: its natural history. Archives of disease in childhood. 1971;46:559-60.

7. Zuker RM, Buenechea R. Congenital epulis: review of the literature and case report. J Oral Maxillofac Surg. 1993;51:1040-3.

8. Vered M, Dobriyan A, Buchner A. Congenital granular cell epulis presents an immunohistochemical profile that distinguishes it from the granular cell tumor of the adult. Virchows Arch. 2009;454:30310.

9. Vered M, Carpenter WM, Buchner A. Granular cell tumor of the oral cavity: updated immunohistochemical profile. J Oral Pathol Med. 2009;38:1509.

10. Damm DD, Cibull ML, Geissler RH, Neville BW, Bowden CM, Lehmann JE. Investigation into the histogenesis of congenital epulis of the newborn. Oral Surg Oral Med Oral Pathol. 1993;76:205-12.

11. Loyola AM, Gatti AF, Pinto DS, Jr., Mesquita RA. Alveolar and extra-alveolar granular cell lesions of the newborn: report of case and review of literature. Oral Surg Oral Med Oral Pathol Oral Radiol Endod. 1997;84:668-71.

12. Nakata M, Anno K, Matsumori LT, Sumie M, Sase $\mathrm{M}$, Nakano $\mathrm{T}$, et al. Prenatal diagnosis of congenital epulis: a case report. Ultrasound in obstetrics \& gynecology : the official journal of the International Society of Ultrasound in Obstetrics and Gynecology. 2002;20:627-9.

13. Kim ES, Gross TL. Prenatal ultrasound detection of a congenital epulis in a triple $X$ female fetus: a case report. Prenatal diagnosis. 1999;19:774-6. 